\title{
Improving the flame retardancy of flax fabrics by radiation grafting of phosphorus compounds
}

\author{
Rodolphe Sonnier*, Belkacem Otazaghine, Amandine Viretto, Guilherme Apolinario, \\ Patrick Ienny
}

C2MA, Ecole des Mines d'Alès, 6, avenue de Clavières, 30100 Alès, France

\begin{abstract}
A B S T R A C T
Two phosphorus-based molecules were grafted onto flax fibers through electron beam irradiation in order to impart flame retardancy to flax fabrics. Fabrics were impregnated by dipping them into a solution containing a phosphonated monomer: dimethyl(methacryloxy)methyl phosphonate (MAPC1) or dimethylvinyl phosphonate (MVP). Then fabrics were irradiated at a dose ranging between 10 and $100 \mathrm{kGy}$. The grafting efficiency was found to be dependent on the molecule concentration in the impregnation solution, on the radiation dose and on the nature of the monomer. In particular, it has been observed that MAPC1 is grafted only onto the surface while MVP is also grafted into the bulk leading to high phosphorus content ( $4 \mathrm{wt} \%$ ). Flame retardancy of the modified flax fibers, fabrics and polyester thermoset composites containing these fabrics were also investigated. High phosphorus content allows fabrics to achieve self-extinguishing behavior. The flammability of composites in cone calorimeter test is also reduced, even if the thermoset is not flame retarded itself.
\end{abstract}

Keywords:

Electron beam

Radiation grafting

Flax fibers

Phosphorus

Flame retardancy

\section{Introduction}

After many years of high-tech development of artificial fibers such as carbon, aramid or glass, today's market trends are moving to the natural fibers [1]. The use of natural reinforcements in composite materials has considerably increased due to their numerous advantages [2-4]: renewability, biodegradability, low cost, low density, low abrasiveness (compared to fiberglass) and good mechanical properties. However, some disadvantages limit their industrial applications such as low compatibility with hydrophobic polymer matrix, the thermal sensitivity at the temperature of compounding process and the flammability $[4,5]$.

Fiber surface modification could be a good alternative to solve several drawbacks of natural fibers like fiber-matrix compatibility and the flammability. The fiber surface modification can be performed by various treatments [1,6-8]: impregnation, chemical coupling (including silane [9,10]) corona [11,12], plasma [13,14], UV irradiation [15], gamma or electron beam irradiation [16-18].

Flammability of naturel fibers and biocomposites has already been reviewed $[5,19,20]$. Among different strategies to impart flame retardancy to natural fibers, phosphorus-based compounds have been pointed out. Suardana et al. have treated jute and coconut fibers with diammonium phosphate (DAP) [21]. The flame retardancy of polypropylene (PP) and poly(lactic

\footnotetext{
* Corresponding author.

E-mail address: rodolphe.sonnier@mines-ales.fr (R. Sonnier).
} 
acid) (PLA) composites containing these modified fibers was improved with the increasing DAP content. Matko et al. have also modified lignocellulosic fillers with DAP and incorporated them into polyurethane [10]. Limiting Oxygen Index (LOI) was significantly higher with the phosphorylation of fillers. A slight improvement of the flame retardancy of a PLA/thermoplastic starch blend containing flax fibers was achieved when fibers were previously treated with a phosphorus silane [9]. Dorez et al. have improved the flame retardancy of biocomposites by modifying flax fibers with various phosphorus-based compounds $[22,23]$. Moreover they proved that phosphonic acid can be efficiently grafted by reacting with hydroxyl groups of flax fibers surface [24]. Shimao et al. have flame retarded PLA composites containing ramie fiber with ammonium polyphosphate (APP) [25]. When APP is located only in the sizing of fiber, LOI increases from 19.1 to 25 but the composite is still unclassified according to UL-94 test. Rating V0 is obtained when APP is added into the matrix. Finally, when APP is present both in the matrix and in the fiber sizing, LOI reaches 35.6 and the composite is rated V0. Then the best performances are obtained when the fiber is flame retarded in addition to the matrix.

Several authors have also used the ionizing radiation to graft compounds (including flame retardants) onto fibers. A first method to graft molecules onto lignocellulosic fibers is called pre-irradiation. Khan has studied the grafting efficiency of methyl methacrylate (MMA) in pre-irradiated jute fibers [16]. Fibers must be maintained at low temperature $\left(-20^{\circ} \mathrm{C}\right)$ to preserve the radicals and peroxides after irradiation. The fibers are then immersed in the solution containing MMA. The grafting content reaches $70 \mathrm{wt} \%$ at $100 \mathrm{kGy}$ in air when MMA concentration is fixed to $10 \mathrm{wt} \%$. Nevertheless, to obtain such value, temperature must be as high as $70^{\circ} \mathrm{C}$. On the contrary, the grafting weight is close to $0 \%$ at $40^{\circ} \mathrm{C}$.

A second method consists in irradiating and grafting simultaneously. Fibers are firstly immersed in a solution containing the molecule to be grafted. After solvent evaporation, fibers are irradiated and grafting occurs during this treatment. Subsequent washing allows removing all non-grafted molecules. In the seventies, Liepins et al. have attempted to graft various bromine or phosphorus-based flame retardants onto poly(ethylene terephthalate) (PET) fibers by gamma irradiation $[26,27]$. According to the used procedure, they were able to graft only onto the surface, uniformly into the fiber or even only in the core. The location of the flame retardant and its nature were the two most important parameters influencing the flame retardancy (assessed only from limiting oxygen index measurements). Harris et al. have also grafted copolymer of vinyl phosphonate oligomer and N-methylolacrylamide (NMA) onto cotton fabric using an irradiation method. NMA promotes the grafting of the phosphonate monomer [17]. Phosphorus was located within fibrous cross section and the polymer add-on reached $46 \mathrm{wt} \%$ for a total monomer conversion at only $23 \mathrm{kGy}$. Mey-Maron et al. have grafted bromostyrene to polyester fabric using both pre-irradiation and simultaneous irradiation [28]. The amount of polybromostyrene grafted onto fabric reaches $19.3 \mathrm{wt} \%$ when fibers were pre-irradiated at $89 \mathrm{kGy}$. Simultaneous irradiation was much more efficient with $30.9 \mathrm{wt} \%$ of grafted polybromostyrene at only $35 \mathrm{kGy}$. The radiation grafting of vinyl phosphonate oligomer was also used by Kaji et al. to impart flame retardancy to a polyethylene open-cell foam [29]. Conversion of monomer was close to $97 \%$ and the degree of grafting was around 55\%. Phosphonate was coating on the inner surface of the foam cell.

According to some works previously reported, vinyl phosphonates appear as good candidates to be radiation grafted onto fibers in order to improve their flame retardancy. In this study, we will manage the radiation grafting of two vinyl phosphonates (namely MAPC1 and MVP) onto flax fabrics and we will characterize the flammability of these modified fabrics. Finally the flame retardancy of thermoset composites containing these fabrics will be also assessed.

\section{Experimental}

\subsection{Materials}

Flax fabrics were kindly provided by Hexcel. The weight of fabrics was $200 \mathrm{~g} / \mathrm{m}^{2}$. The composition of flax fibers is $81 \mathrm{wt} \%$ of cellulose, $13 \mathrm{wt} \%$ of hemicellulose and $2.7 \mathrm{wt} \%$ of lignin in good agreement with the literature [30-33].

Dimethyl(methacryloxy)methyl phosphonate (MAPC1) (Specific Polymer), dimethylvinyl phosphonate (MVP) (see Fig. 1), tetrahydrofurane (Fisher Scientific) and ethanol (Fisher Scientific) were used as received without any purification.

The resin used in this study was a DCPD (dicyclopentadiene) isophtalic unsaturated polyester, Enydyne N50, supplied by Cray Valley. The matrix was polymerized with $1.8 \% \mathrm{w} / \mathrm{w}$ of methyl ethyl ketone peroxide (MEKP - Luperox K1S).

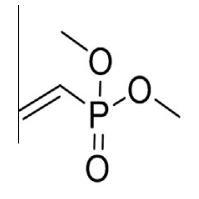

MVP

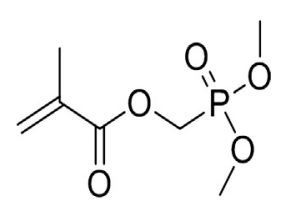

MAPC1

Fig. 1. Phosphorus-based molecules used in this study. 


\subsection{Fiber grafting}

\subsubsection{General procedure for the fabrics impregnation with a phosphonated monomer}

In a first step the flax fabrics were dipped $1 \mathrm{~min}$ into a solution of MVP (or MAPC1) and THF. The concentration of the phosphonated monomer was adjusted to achieve a weight percentage of $0.1 \%, 1 \%$ or $10 \%$. In a second step the fabrics were placed under a laboratory extractor hood to remove the solvent (THF). Samples were weighted before and after impregnation to evaluate the amount of monomer introduced. In order to verify the stability of the flax fibers during this procedure of impregnation, different tests were done. The first one was an impregnation test using only THF (without phosphorus-based molecule). The second ones were impregnation tests using solutions of MVP or MAPC1 at $10 \mathrm{wt} \%$ followed by THF washing. These tests were done to verify the absence of weight loss due to a solubilization of some components present on the flax fiber.

\subsubsection{Irradiation of the impregnated flax fabrics}

Fibers were irradiated in air at room temperature using an electron beam accelerator (energy $9.8 \mathrm{MeV}$ ) by Ionisos SA (Chaumesnil, France). Doses were chosen in the range 10-100 kGy.

Grafting content was assessed firstly by weighing. Indeed samples were weighted before and after impregnation with the phosphonated monomer but also after the irradiation step before and after washing with THF and ethanol. Ethanol was chosen because poly(MAPC1) and poly(MVP) show better solubility in this solvent than in THF. The weighing directly after irradiation was carried out to verify the absence of weight loss due to molecule evaporating. The weighting after washing the irradiated sample was carried out to evaluate the quantity of grafted phosphonated molecule.

The phosphorus content was also measured by inductively coupled plasma atomic emission spectroscopy (ICP-AES). Measurements were carried out by SGS Multilab.

Samples were called according to the flame retardant grafted (MAPC1 or MVP) and phosphorus content measured by ICP-AES. For instance, F-MAPC1-0.34 refers to flax fibers modified with MAPC1 and containing 0.34 wt\% of phosphorus. Table 1 shows the conditions of grafting and the phosphorus content (measured by ICP-AES) for all modified flax fabrics.

\subsection{Preparation of composites}

All composite sheets were processed using vacuum infusion technique under controlled conditions $\left(48 \% \mathrm{rh}, 23^{\circ} \mathrm{C}\right)$. Seven layers of flax fabrics $\left(300 \times 300 \mathrm{~mm}^{2}\right)$ were impregnated with a polyester resin and stacked over a glass mold. After the infusion step, the composites were cured at room temperature for $24 \mathrm{~h}$, then a post-curing step took place in an oven at $80^{\circ} \mathrm{C}$ for $3 \mathrm{~h}$. Composites of around $3.3 \mathrm{~mm}$ thick and $27 \mathrm{vol} \%$ of fibers were obtained.

The composites were called PES/F, PES/F-MAPC1 and PES/F-MVP. The phosphorus content in F-MAPC1 and F-MVP was 0.25 and $4.1 \mathrm{wt} \%$ respectively.

\subsection{Characterizations}

\subsubsection{Scanning electron microscopy (SEM) coupled EDX analyses}

The micrographs of the fibers were obtained using an environmental scanning electron microscope (FEI Quanta 200). For this study, the fibers have been cut while avoiding damaging them by stretching or crushing. Then they were deposited on an adhesive wafer so that the facies are at the edge of the wafer. They were metallized in high vacuum sputtering metallizer Bal-Tec CED 030 Balzers in order to ensure their stability during the analysis. The so prepared fibers were analyzed using a vertical sample holder and the micrographs were obtained under high vacuum at a voltage of $7 \mathrm{kV}$, with a spot size lower than $1 \mu \mathrm{m}$ and a working distance of $10 \mathrm{~mm}$. The environmental SEM was equipped with an Oxford energy-dispersive X-ray spectroscopy (EDX) sensor which enables to carry out elemental imaging on fibers.

\subsubsection{Pyrolysis combustion flow calorimetry}

The pyrolysis combustion flow calorimetry (PCFC) is used to assess the flammability of samples at microscale (2-3 mg). This device was developed by Lyon et al. [34]. The sample was first heated from 80 to $750{ }^{\circ} \mathrm{C}$ at $1{ }^{\circ} \mathrm{C} / \mathrm{s}$ in a pyrolyzer under nitrogen flow (anaerobic pyrolysis - method A according to the standard ASTM D7309) and the degradation products were sent to a combustor where they mixed with oxygen in excess at $900^{\circ} \mathrm{C}$. In such conditions, all gases were fully oxidized. Heat release rate (HRR) was then calculated by oxygen depletion according to Huggett's relation ( $1 \mathrm{~kg}$ of consumed oxygen corresponds to $13.1 \mathrm{MJ}$ of released energy) [35]. In another series of experiments, some fibers were studied according to method B (aerobic pyrolysis in 80/20 nitrogen/oxygen flow).

As evidenced by Yang et al. [36], PCFC can be used to assess the flame retardancy of textiles if fibers are ground into homogeneous powders to improve sample uniformity. In our study, fibers were cut into smaller particles and some samples were tested several times to check that the measurements were reproducible.

\subsubsection{Preliminary fire test on fabrics}

An unstandardized fire test was carried out to assess the flammability of some fabrics. Briefly small pieces of fabrics (around $0.5 \mathrm{~g}$ ) are pinched between two glass plates and maintained vertically. A lighter is used to ignite the top of fabrics. 
Table 1

Conditions of grafting and phosphorus content for all modified fibers.

\begin{tabular}{|c|c|c|c|c|}
\hline Fiber & Phosphorus FR & Dose (kGy) & FR concentration in impregnation solution (wt\%) & Phosphorus content (wt\%) \\
\hline F-untreated-0.01 & 1 & 1 & 1 & 0.01 \\
\hline F-MAPC1-0.11 & MAPC1 & 50 & 0.1 & 0.11 \\
\hline F-MAPC $1-0.18$ & MAPC1 & 50 & 1 & 0.18 \\
\hline F-MAPC1-0.17 & MAPC1 & 10 & 10 & 0.17 \\
\hline F-MAPC1-0.16 & MAPC1 & 20 & 10 & 0.16 \\
\hline F-MAPC1-0.25 & MAPC1 & 50 & 10 & 0.25 \\
\hline F-MAPC1-0.34 & MAPC1 & 100 & 10 & 0.34 \\
\hline F-MVP-0.09 & MVP & 50 & 0.1 & 0.09 \\
\hline F-MVP-0.48 & MVP & 50 & 1 & 0.48 \\
\hline F-MVP-3.4 & MVP & 10 & 10 & 3.4 \\
\hline F-MVP-4.0 & MVP & 20 & 10 & 4.0 \\
\hline F-MVP-4.1 & MVP & 50 & 10 & 4.1 \\
\hline F-MVP-3.9 & MVP & 100 & 10 & 3.9 \\
\hline
\end{tabular}

a Measured by ICP-AES.

This device allows assessing if the fabric is self-extinguishing. The residue is also weighted after complete burning (for self-extinguishing fabric, complete burning is reached by multiple flame applications).

\subsubsection{Cone calorimetry}

A cone calorimeter (Fire Testing Technology) was used to assess the flammability at bench scale. Horizontal sample of $100 \times 100 \times 4 \mathrm{~mm}^{3}$ was placed at $2.5 \mathrm{~cm}$ below a conic heater and was exposed to a $30 \mathrm{~kW} / \mathrm{m}^{2}$ radiant heat flux in well-ventilated conditions (air rate $24 \mathrm{~L} / \mathrm{s}$ ) and in the presence of a spark igniter to force the ignition. As in PCFC test, HRR was determined according to oxygen depletion (Huggett's relation [35]). This test was performed according to the ISO 5660 standard. Time-to-ignition (TTI), peak of heat release rate (pHRR), total heat release (THR), residue yield and effective heat of combustion (EHC) were recorded.

\section{Results and discussion}

The first part of this study deals with the characterization of flax fibers grafted with MAPC1 or MVP. Then the flame retardancy of flax fibers, fabrics and composites containing these fabrics was assessed.

\subsection{Grafting of MAPC1 and MVP onto flax fibers}

Radiation grafting was chosen to bond phosphorus molecules covalently onto flax fibers to ensure a thermal stability compatible with polymer processing. Ethanol and THF washings allow removing unreacted monomers and oligomer or polymer chains unbound to fibers. To check that these washings were efficient, PCFC analysis was carried out on F-MAPC1-0.25 before and after washing ( 0.25 refers to the phosphorus content measured by ICP-AES after washing). Fig. 2 shows the HRR curves for both cases. Before washing, a small peak of heat release rate is observed between 100 and $200{ }^{\circ} \mathrm{C}$, that prevents the incorporation of such fibers into polymer matrix. A second small peak is observed at $270{ }^{\circ} \mathrm{C}$. These peaks are due to non-grafted MAPC1 molecules or oligomers which can be released at low temperature. The main degradation peak is strongly shifted to lower temperature, and its intensity is low, due to the high content of MAPC1 (grafted and non-grafted MAPC1 molecules are present in the fiber). After washing, the small peaks at low temperature disappear. The degradation starts at $250^{\circ} \mathrm{C}$ allowing the incorporation of fibers into most of polymers. All modified fibers exhibit similar thermal stability and no one shows the presence of unreacted molecules.

Grafting efficiency was assessed as the ratio between the weight increases after irradiation and after subsequent washing (Table 2). The grafting efficiency of MAPC1 is moderate $(0.35-0.47 \%)$ at low monomer concentration in the solution but decreases strongly at higher concentration $(0.08-0.15 \%)$. The weight increase after washing is approximately constant for all fibers despite the much higher weight increase after impregnation and irradiation. It means that in this case, most of MAPC1 is not grafted to fibers after irradiation and is removed by washing. This result can be related to the presence of MAPC1 only on the fiber surface and not in the bulk (as evidenced in the following). Therefore the amount of grafted MAPC1 is limited by the surface area of the fiber. The surface is easily saturated even at low concentration of MAPC1. At higher MAPC1 concentration, a higher amount of molecules is deposited on the surface during impregnation but many molecules are not close enough to fiber components to be grafted during irradiation. Therefore these additional molecules are removed by washing.

On the contrary, the grafting efficiency of MVP is much higher and increases with the MVP concentration in the solution. MVP is grafted into the bulk (see below). Therefore its grafting is not limited by the surface area of fiber.

The grafting efficiency also increases with the radiation dose. A higher concentration of free radicals leads to more phosphorus-based molecules grafted. 


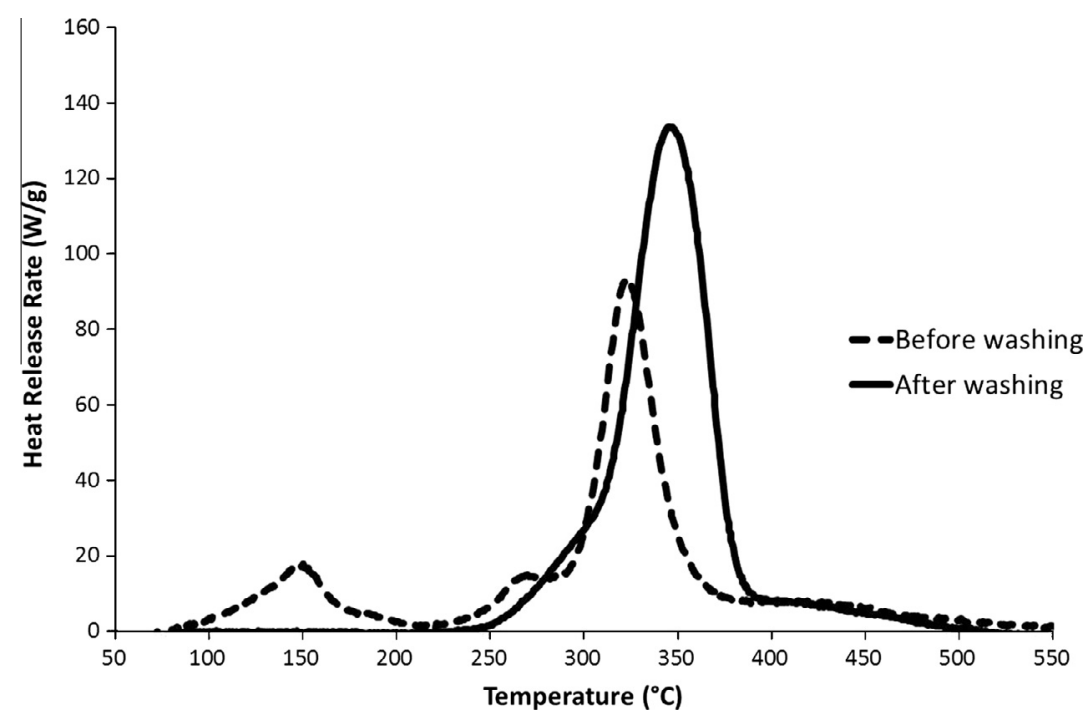

Fig. 2. Heat release rate curves of F-MAPC1-0.25 before and after washing.

Table 2

Change in weight (in comparison to initial weight) and grafting efficiency for all fibers studied.

\begin{tabular}{|c|c|c|c|c|c|}
\hline \multirow[t]{2}{*}{ Fiber } & \multirow[t]{2}{*}{ Dose (kGy) } & \multirow[t]{2}{*}{ FR concentration in impregnation solution (wt\%) } & \multicolumn{2}{|c|}{ Change in weight (\%) } & \multirow[t]{2}{*}{ Grafting efficiency } \\
\hline & & & After irradiation & After washing & \\
\hline F-untreated-0.01 & 1 & 1 & 1 & 1 & 1 \\
\hline F-MAPC1-0.11 & 50 & 0.1 & +2 & +0.7 & 0.35 \\
\hline F-MAPC1-0.18 & 50 & 1 & +1.9 & +0.9 & 0.47 \\
\hline F-MAPC1-0.17 & 10 & 10 & +13.2 & +1.0 & 0.08 \\
\hline F-MAPC1-0.16 & 20 & 10 & +12.5 & +1.2 & 0.10 \\
\hline F-MAPC1-0.25 & 50 & 10 & +13.4 & +1.3 & 0.10 \\
\hline F-MAPC1-0.34 & 100 & 10 & +13.6 & +2.0 & 0.15 \\
\hline F-MVP-0.09 & 50 & 0.1 & +0.49 & +0.30 & 0.61 \\
\hline F-MVP-0.48 & 50 & 1 & +1.90 & +1.50 & 0.79 \\
\hline F-MVP-3.4 & 10 & 10 & +15.1 & +10.6 & 0.70 \\
\hline F-MVP-4.0 & 20 & 10 & +14.8 & +12.4 & 0.84 \\
\hline F-MVP-4.1 & 50 & 10 & +13.4 & +12.3 & 0.92 \\
\hline F-MVP-3.9 & 100 & 10 & +15.3 & +14.5 & 0.95 \\
\hline
\end{tabular}

Grafting content was assessed using two methods: elemental analysis by ICP-AES and weighing. Fig. 3 allows comparing the phosphorus content measured from both methods. It appears that the values are in good agreement for low phosphorus content. On the contrary, for higher phosphorus content, weighing underestimates the grafting. It may be due to a modification of the water absorption of flax fibers. Indeed, when the grafting content is high (3-4 wt\% of phosphorus corresponds to 13-18 wt\% of MVP), the water absorption may be lower due to the presence of the phosphonated molecule. A fraction of this water was replaced by polymer chains of poly(MVP), disturbing the measurement of the weight increase due to the grafting. In the following, only phosphorus content measured by ICP-AES was considered.

Fig. 4 shows the phosphorus content grafted on flax fibers for various radiation doses when monomer concentration was fixed to $10 \mathrm{wt} \%$ in the impregnation solution. Grafting of MAPC1 leads only to very low phosphorus content (0.34 wt\% at $100 \mathrm{kGy}$, i.e. $2.3 \mathrm{wt} \%$ of MAPC1). On the contrary high content of phosphorus can be reached with MVP (up to 4 wt\% of phosphorus, i.e. $18 \mathrm{wt} \%$ of MVP). It also appears that low radiation doses are enough to reach such grafting content: 4 wt\% of phosphorus is reached in the range 20-100 kGy in the case of MVP grafting. This result is very promising because lignocellulosic compounds are very sensitive to radiation degradation. Therefore, it is important to minimize the radiation dose needed to graft flame retardants. Hence Khan et al. have shown that $\gamma$-irradiation leads to a significant decrease of mechanical properties of jute fibers [37]: relative elongation at break and tensile strength drop of $15 \%$ and $20 \%$ respectively with a dose of $50 \mathrm{kGy}$. The decrease is less than $10 \%$ at a low dose of $10 \mathrm{kGy}$.

Fig. 5 highlights the great influence of monomer concentration on the MVP grafting efficiency. The phosphorus content ranges over two orders of magnitude (from 0.09 to 4 wt\% when monomer concentration increased from 0.1 to $10 \mathrm{wt} \%$ ). Such influence allows a precise control of grafting. On the contrary, there is only little influence of monomer concentration on the MAPC1 grafting. 


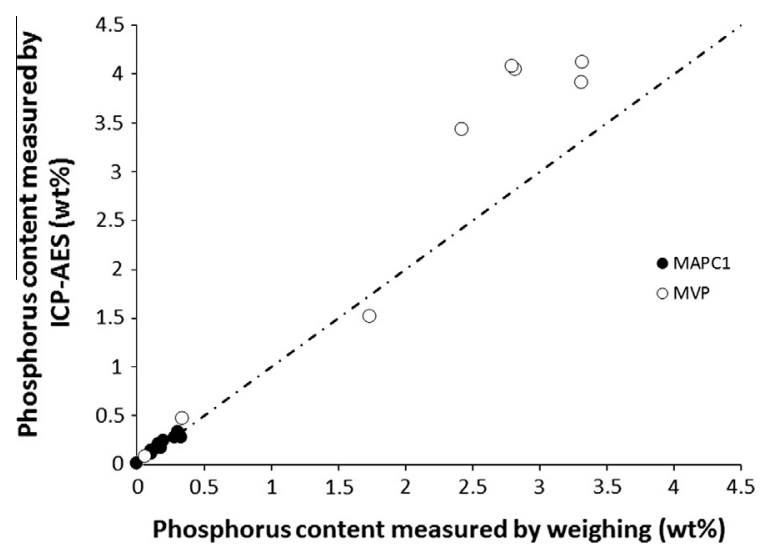

Fig. 3. Comparison of phosphorus contents measured by ICP-AES and weighing.

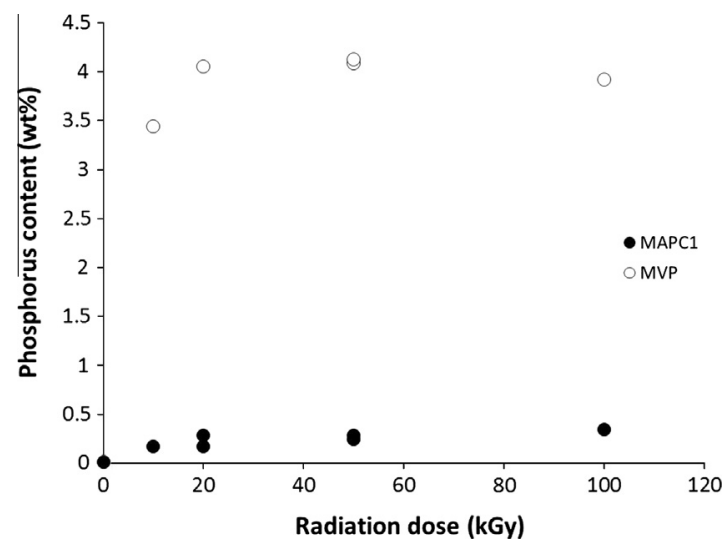

Fig. 4. Influence of radiation dose on phosphorus content for flax fabrics impregnated with a solution containing $10 \%$ of monomer.

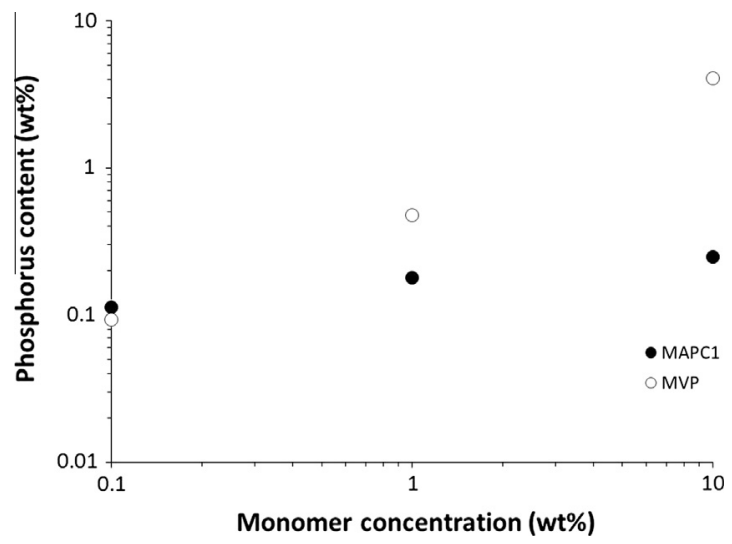

Fig. 5. Influence of monomer concentration on phosphorus content (radiation dose $50 \mathrm{kGy}$ ).

The characterization of fibers by SEM-EDX has enabled to observe differences on the location of the phosphorus grafting on the fiber (Figs. 6 and 7). MAPC1 grafting induces the presence of phosphorus only on the fiber surface without penetration of MAPC1 into the bulk. On the contrary, the phosphorus is present from the surface to the bulk of fibers modified by MVP. In some cases, the extreme center of large fibers is depleted in phosphorus (see Fig. 7B). Such difference explains the large gap between the phosphorus content of flax fibers modified by MAPC1 and MVP. The penetration of MVP into the fibers during 

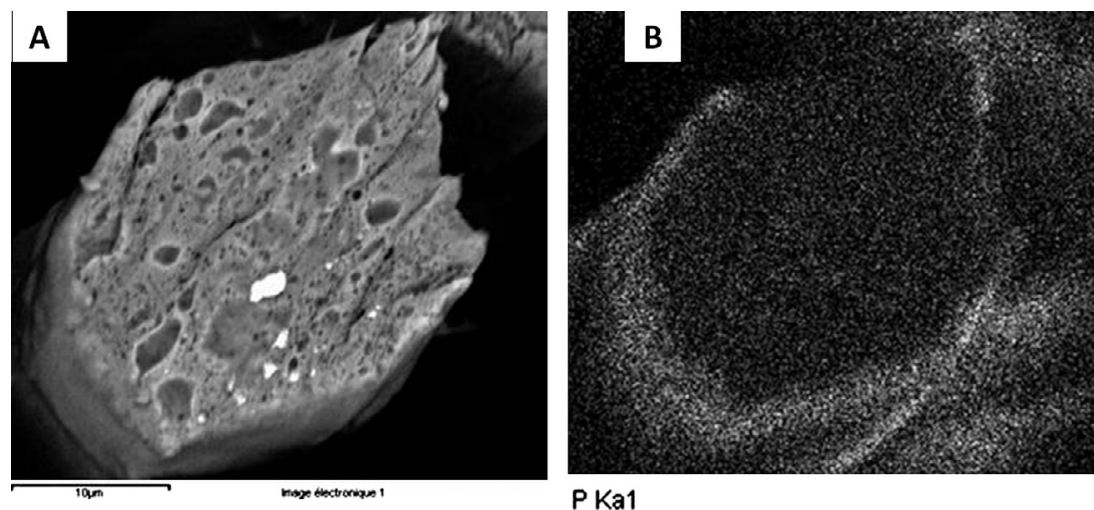

P Ka1

Fig. 6. (A) SEM observations of flax fibers grafted by MAPC1 and (B) phosphorus imaging using EDX analysis.
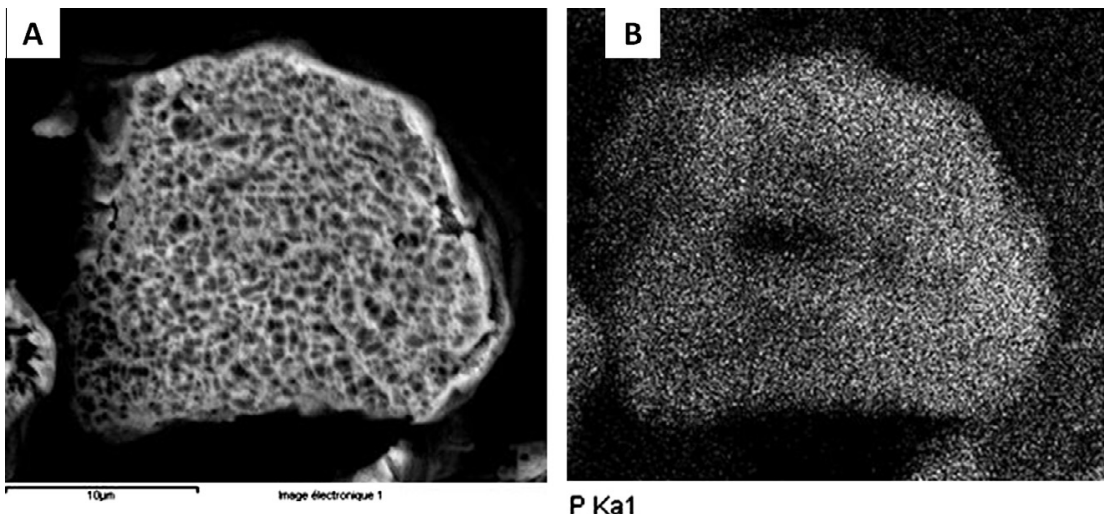

P Ka1

Fig. 7. (A) SEM observations of flax fibers grafted by MVP and (B) phosphorus imaging using EDX analysis.

impregnation allows a high grafting content by e-beam irradiation. The reason why only MVP (and not MAPC1) can penetrate during impregnation is unclear. Further work is needed to understand this point and to attempt controlling the penetration of molecules into the flax fibers.

Dorez et al. have grafted polymers chains of hydrolyzed MAPC1 [22]. In their study, phosphorus-based groups are not phosphonates but phosphonic acids allowing an efficient grafting onto flax fibers: the hydroxyl groups on fibers react covalently with the phosphonic acid functions of the polymer. The phosphorus content reached with this method was $2.55 \mathrm{wt} \%$. The location of phosphorus was not assessed. Another phosphonate molecule (octadecylphosphonic acid) was also grafted on flax fibers. The location was studied using SEM/EDX. The molecule was only present on the fiber surface [24].

As already reported, Liepins et al. have grafted various vinyl phosphonates onto PET fibers, including MVP [27]. To obtain a grafting into the bulk, fibers were preswollen in ethylene dichloride at $70^{\circ} \mathrm{C}$ during $30 \mathrm{~min}$. Such preswelling does not appear necessary for flax fibers, at least if the molecule to be grafted is MVP. The authors also mentioned that MVP needs to be combined with ethyl acetate solution of anhydrous $\mathrm{ZnCl}_{2}$ to be grafted properly (grafting efficiency: 27 wt\%). It was not the case in our study (highest grafting efficiency: $18 \mathrm{wt} \%$ ).

\subsection{Phosphorus effect on fiber flammability}

Flame retardancy of flax fibers was studied using pyrolysis combustion flow calorimeter (anaerobic pyrolysis). Typical heat release rate (HRR) curves are shown in Fig. 8. Unmodified flax fibers degrade in one step. The peak of heat release rate (pHRR) occurs at about $350^{\circ} \mathrm{C}$ and its value is around $160 \mathrm{~W} / \mathrm{g}$. Total heat release (THR) is close to $8 \mathrm{~kJ} / \mathrm{g}$. These values are quite different to those obtained by Dorez et al. (pHRR $115 \mathrm{~W} / \mathrm{g}$, THR $5.8 \mathrm{~kJ} / \mathrm{g}$ and temperature at pHRR $371{ }^{\circ} \mathrm{C}$ ) [33]. The authors have examined the change in flammability properties of various natural fibers according to their composition (cellulose, hemicellulose and lignin). They found that these properties are influenced by the composition but not only. In particular, flax fibers exhibited a high char yield despite low lignin content. Other parameters must be taken into account, as for example the structure of the fibers. It may be a reason of such discrepancy between the values found by Dorez et al. and our values. Moreover, it must be kept in mind that THR of flax fibers measured by other methods (as for example cone 


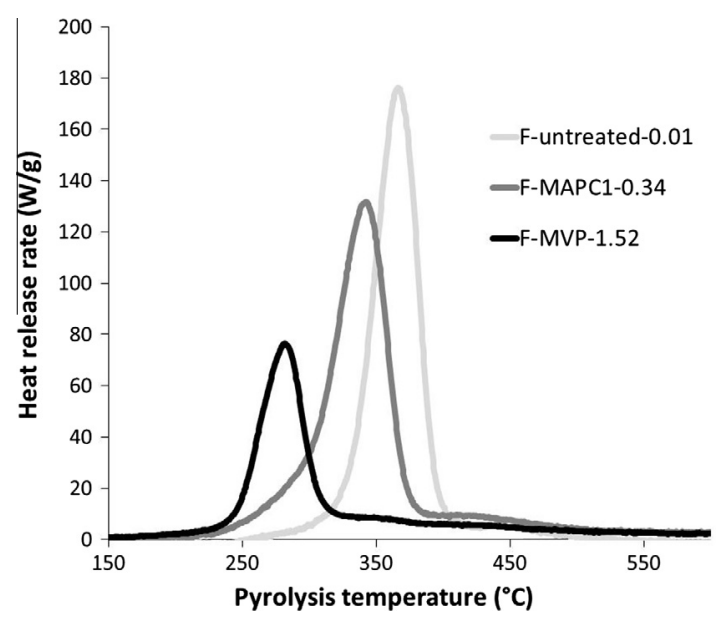

Fig. 8. HRR curves of various flax fibers using PCFC (anaerobic pyrolysis).

calorimeter) cannot be easily compared to our values. Indeed, in cone calorimeter, flax fibers can be thermo-oxidized at the end of the test.

MAPC1 grafting leads to a slight decrease in PHRR. Temperature at pHRR also decreases in a small extent. THR remains constant. MVP leads to more significant changes: PHRR and temperature at pHRR strongly decrease. THR is also lowered. The differences between MVP and MAPC1-grafted flax fibers may be mainly due to the difference in phosphorus content. The flax fibers modified with the lowest content of MVP (F-MVP-0.09) exhibit performances close to those of fibers modified with MAPC1. Therefore in the following, PCFC results are discussed in light of the phosphorus content.

Nevertheless, it is not excluded that other parameters as the location of phosphorus or the nature of the phosphorus-based molecule have also an influence. Hence, Liepins et al. have measured the limiting oxygen index (LOI) of PET fibers flame retarded with diethyl vinyl phosphonate (DEVP) [27]. LOI reached 23.2 or 24.3 if DEVP was located on the fiber surface (through coating or grafting processes) but a slightly higher value (27.6) when DEVP was grafted into the bulk despite a lower DEVP content (16 wt\% versus $18-21 \mathrm{wt} \%$ ).

Figs. 9-11 show the influence of phosphorus content on main data measured using PCFC. The value of pHRR decreases from $160 \mathrm{~W} / \mathrm{g}$ for unmodified flax fiber to less than $20 \mathrm{~W} / \mathrm{g}$ for fibers modified with almost $4 \mathrm{wt} \%$ of phosphorus (Fig. 9).

Phosphorus flame retardants are known to decrease the thermal stability of polymers. This is due to the formation of phosphoric acids which catalyze the degradation of polymer backbone. Fig. 10 shows that the temperature at pHRR decreases from 360 to $250{ }^{\circ} \mathrm{C}$ when the phosphorus content increases up to $4 \mathrm{wt} \%$.

THR also decreases when phosphorus content increases (Fig. 11). THR of unmodified flax fibers is close to $8 \mathrm{~kJ} / \mathrm{g}$. THR lowers up to about $1 \mathrm{~kJ} / \mathrm{g}$ for flax fibers containing $4 \mathrm{wt} \%$ of phosphorus. This is obviously due to a high char content promoted by the presence of phosphorus.

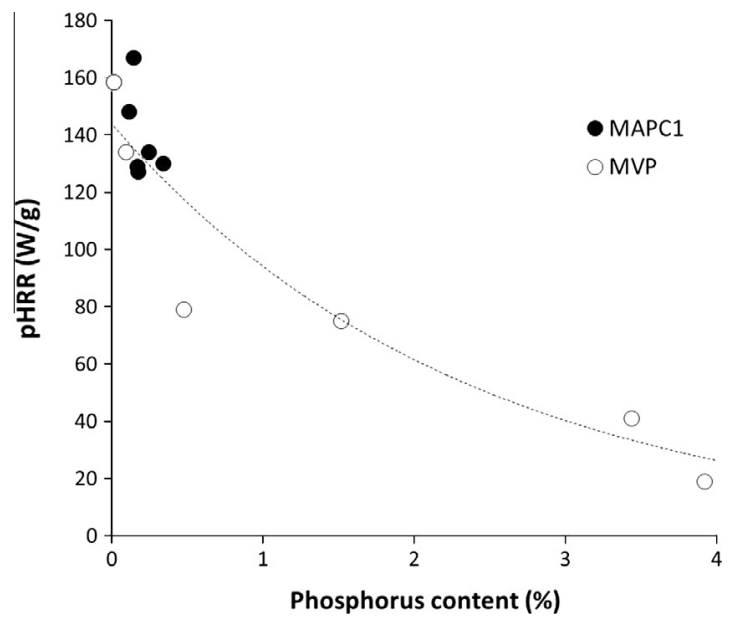

Fig. 9. Influence of phosphorus content on values of pHRR of flax fibers using PCFC (dotted line is only a guideline for eyes). 


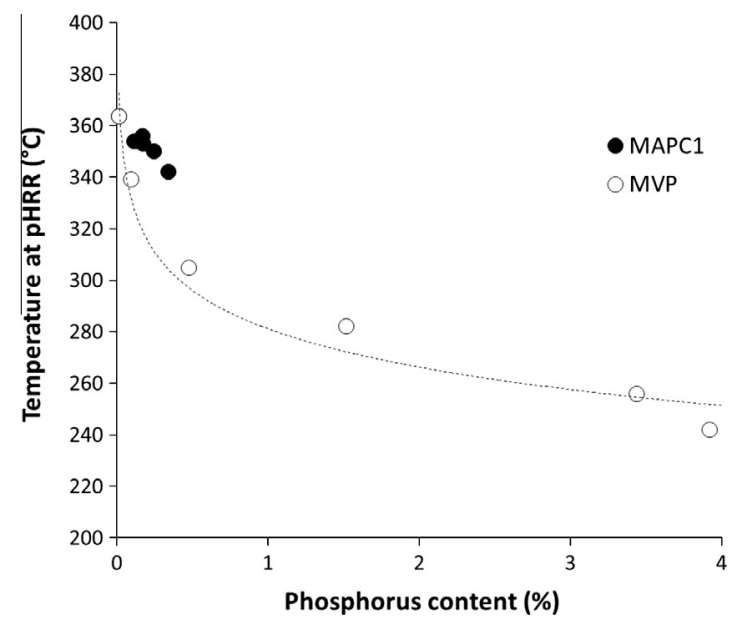

Fig. 10. Influence of phosphorus content on temperature at pHRR of flax fibers using PCFC (dotted line is only a guideline for eyes).

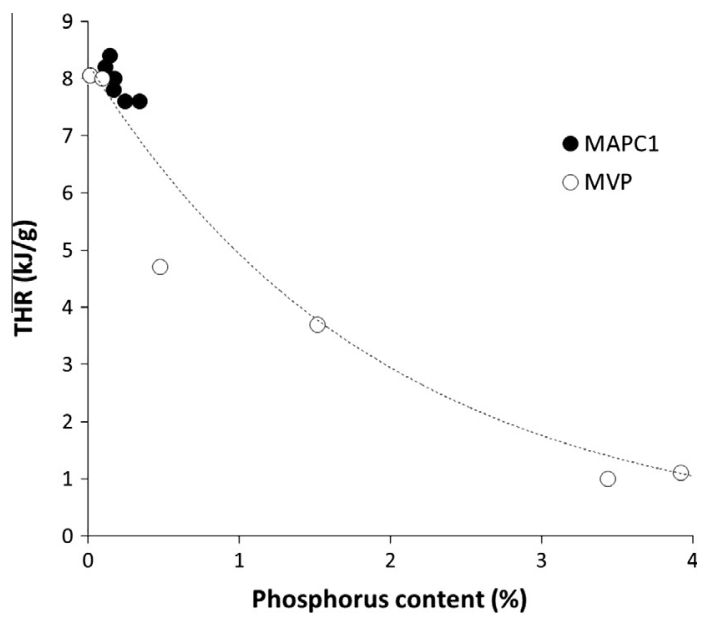

Fig. 11. Influence of phosphorus content on total heat release of flax fibers using PCFC (dotted line is only a guideline for eyes)

According to the PCFC results, it appears that the flammability is mainly controlled by the content of phosphorus grafted on the fibers. MVP is grafted into the bulk of fibers and its content reaches high values ( $4 \mathrm{wt} \%$ of phosphorus i.e. about $18 \%$ of MVP). On the contrary, while MAPC1 does not penetrate into the bulk, its grafting is severely limited (lower than $0.5 \mathrm{wt} \%$ ). Therefore, MAPC1 does not seem improving the flame retardancy of flax fibers. Dorez et al. have observed that hydrolyzed poly(MAPC1) decreases the flammability of flax fibers according to PCFC, but at higher grafting content (2.55 wt\% of phosphorus) [22].

Nevertheless, phosphorus is known not only to promote charring but also to improve the thermo-oxidative stability of the char. Then some PCFC analyses were also carried out in aerobic pyrolysis (Fig. 12). Two peaks can be observed in the HRR curves. The first peak corresponds to the degradation of fibers while the second one is related to the degradation of the char previously formed. It can be observed that phosphorus allows delaying the temperature at which this second peak occurs. Moreover, THR is in the range $12-13 \mathrm{~kJ} / \mathrm{g}$ for unmodified fibers and fibers modified with MAPC1 (0.34 wt\% of phosphorus). Such a value corresponds to the complete degradation of fibers (no residue). But, THR is close to $10.5 \mathrm{~kJ} / \mathrm{g}$ for the flax fibers modified with MVP (1.52 wt\% of phosphorus). It means that char is not fully degraded at $750{ }^{\circ} \mathrm{C}$ (upper temperature of pyrolysis). This can be also confirmed when considering that heat is still released (HRR close to $6 \mathrm{~W} / \mathrm{g}$ ) at the end of pyrolysis ramp.

These results show that MVP but also MAPC1 in some extent enhance the thermal oxidative stability of the char. In other words, low phosphorus content (as in fibers modified with MAPC1) can be beneficial even if it does not influence the anaerobic pyrolysis. 


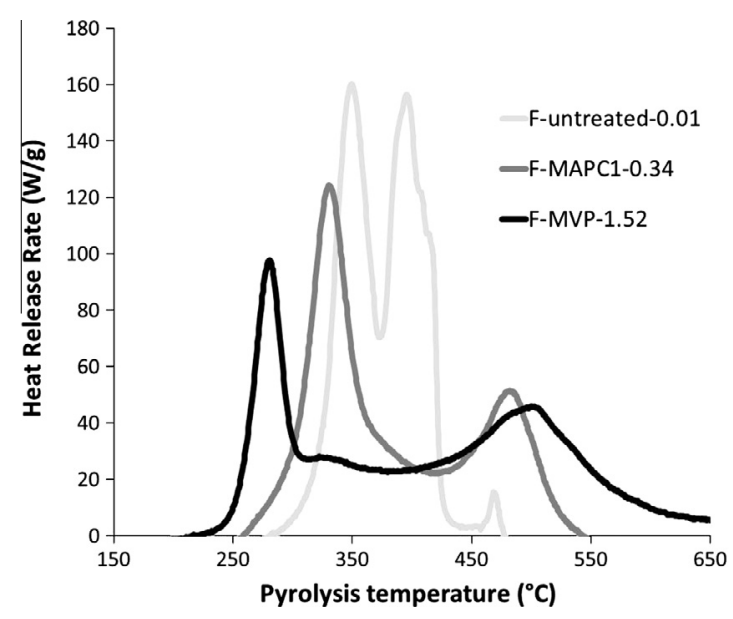

Fig. 12. HRR curves of various flax fibers using PCFC (aerobic pyrolysis).

\subsection{Phosphorus effect on fabric flammability}

An unstandardized test was carried out to assess the self-extinguishment of flax fabrics (Figs. 13 and 14 and Movie 1 in Supporting Information). Ignition is piloted using a small flame from a lighter at the top of the fabric positioned vertically. Once ignited, flame is free to propagate in air atmosphere without any other source of heat. Unmodified flax fabric is non self-extinguishing. Flame propagates through the whole sample leaving a residue which is degraded few seconds later. Char yield is close to $0 \mathrm{wt} \%$.

When fabric was modified with MAPC1 (0.25 wt\% of phosphorus), char is thermally stable and does not degrade. Char yield at the end is $6.8 \mathrm{wt} \%$. This is in good agreement with the improvement of thermo-oxidative stability of char as observed using PCFC. Nevertheless, fabric is still not self-extinguishing.

Finally when fabric is modified with MVP (1.52 wt\% of phosphorus), fabric is self-extinguishing. Flame out occurs almost instantaneously after removal of the piloted flame. If fabric is fully burnt with numerous flame applications, char yield reaches $21.5 \mathrm{wt} \%$.

The results for all tested fabrics are plotted in Fig. 14. It appears that the char content increases roughly linearly with the phosphorus content. Moreover, self-extinguishing behavior is observed for flax fabric containing $1.5 \mathrm{wt} \%$ of phosphorus or more. The minimal content of phosphorus to reach self-extinguishing is ranged between 0.5 and $1.5 \mathrm{wt} \%$. Such value needs a grafting of phosphorus into the fiber bulk and then can be reached only by MVP grafting.

From results showed in Fig. 13, it must not be concluded that charring is responsible on self-extinguishing behavior. Charring is usually the main mode-of-action of phosphorus-based flame retardants. Nevertheless, in our case, phosphorus acts not only as char promoter but also as flame inhibitor (as proved in the following). The self-extinguishing behavior is due to the combination of both modes-of-action.

\subsection{Flame retardancy of composites}

The flame retardancy of unsaturated polyester thermoset composites containing unmodified and modified flax fabrics has been studied with cone calorimeter test at low irradiance $\left(30 \mathrm{~kW} / \mathrm{m}^{2}\right)$. In this article, we will briefly show the performances. The results will be discussed in greater detail in a further article.

In such test, pyrolysis is believed to be mainly anaerobic after ignition. Aerobic pyrolysis occurs only before ignition or after flame out. While MAPC1 grafted on flax fibers has no great effect on HRR curves measured in PCFC according to method A (anaerobic pyrolysis), it can be expected that its effect will be negligible or at least limited on the flammability of composites in cone calorimeter test.

Fig. 15 shows the HRR curves for the three studied composites and Table 3 summarizes the main data recorded. Residues collected after cone test are presented in Fig. 16. As discussed just above, PES/F and PES/F-MAPC1 exhibit very similar curves. There is no significant difference between both composites considering the uncertainties of measurement. Residue yield is very small and corresponds only to flax fabrics. Interestingly, the residue of PES/F-MAPC1 (Fig. 16B) is retracted and heterogeneous.

On the contrary, PES/F-MVP exhibits a much lower flammability: pHRR is reduced by $41 \%$ and THR by $47 \%$. These good performances are due to two phenomena. First, MVP promotes charring of flax fibers and therefore limits the amount of fuels released in gas phase. As observed in Fig. 16C, the high residue yield corresponds only to the charring of fabrics. It does not seem that phosphorus promotes charring of the PES matrix. Moreover, this char residue would not act as barrier to heat and gases according to the profile of the curve. 


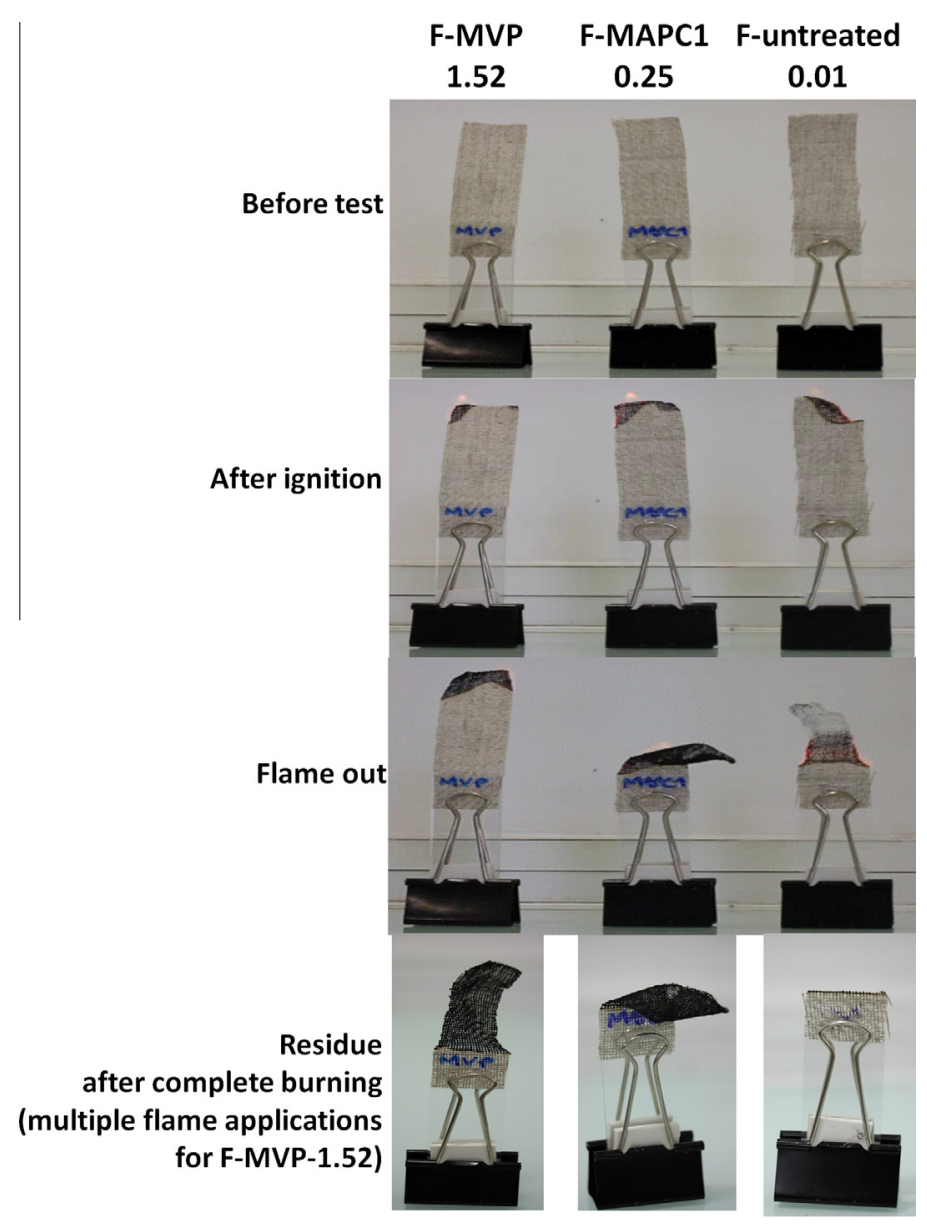

Fig. 13. Description of the preliminary fire test on some flax fabrics.

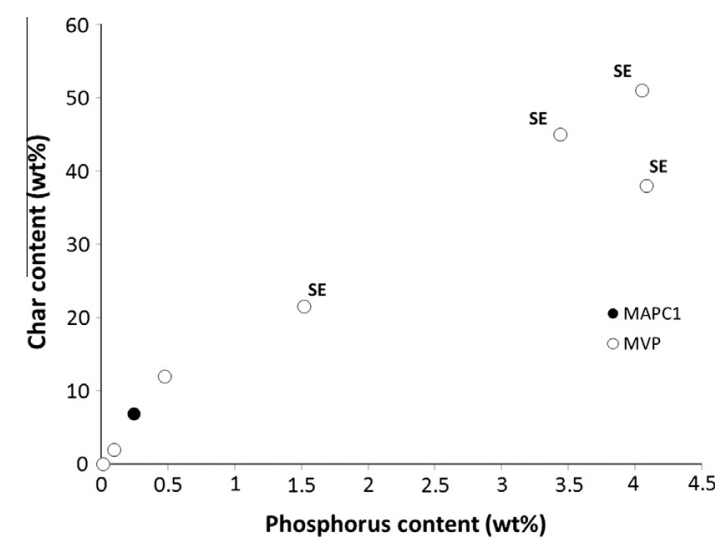

Fig. 14. Results of the preliminary fire test for some flax fabrics (the label SE means that the fabric is self-extinguishing).

Secondly, flame inhibition occurs, as evidenced by the low EHC for PES/F-MVP (and also by the low $\mathrm{CO}_{2}$ production - data not shown). It means that phosphorus is partly released in gas phase and interacts with $\mathrm{OH}^{\circ}$ and $\mathrm{H}^{\circ}$ radicals to slowdown the combustion. The release of phosphorus in gas phase has also been observed using TGA-FTIR coupling (data not shown).

However, ignition occurs earlier ( $20 \mathrm{~s}$ versus $45 \mathrm{~s}$ for PES/F). This is in good agreement with the low thermo-oxidative stability of flax fibers modified with MVP, as observed in PCFC (see Fig. 12). Less heat is needed to reach the temperature of pyrolysis of the fibers F-MVP. Then the release of fuels starts earlier leading to a shorter time-to-ignition. Keep in mind that before ignition degradation occurs in presence of oxygen. 


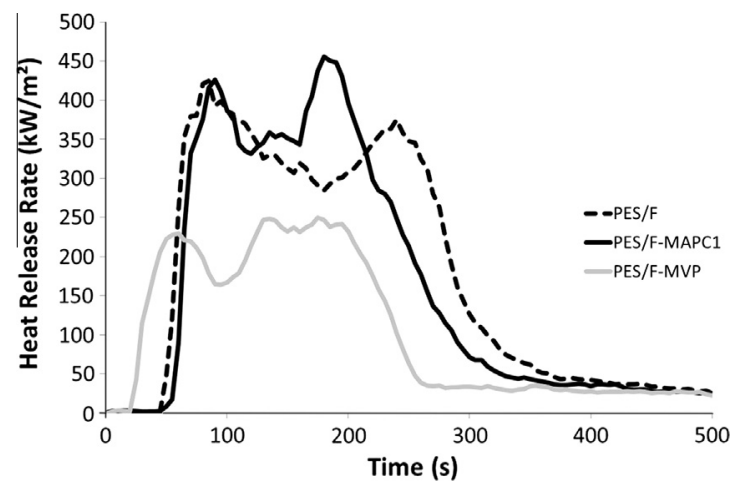

Fig. 15. HRR curves of some composites containing flax fabrics in cone calorimeter test.

Table 3

Main results of cone calorimeter tests.

\begin{tabular}{|c|c|c|c|c|c|}
\hline & TTI (s) & $\mathrm{pHRR}\left(\mathrm{kW} / \mathrm{m}^{2}\right)$ & $\operatorname{THR}\left(\mathrm{MJ} / \mathrm{m}^{2}\right)$ & $\mathrm{EHC}(\mathrm{kJ} / \mathrm{g})$ & Residue yield (wt\%) \\
\hline $\mathrm{PES} / \mathrm{F}$ & 45 & 425 & 92.8 & 22.5 & 1.9 \\
\hline PES/F-MAPC1 & 52 & 456 & 83.4 & 20.5 & 1.9 \\
\hline PES/F-MVP & 20 & 250 & 49.6 & 13.0 & 18.2 \\
\hline
\end{tabular}
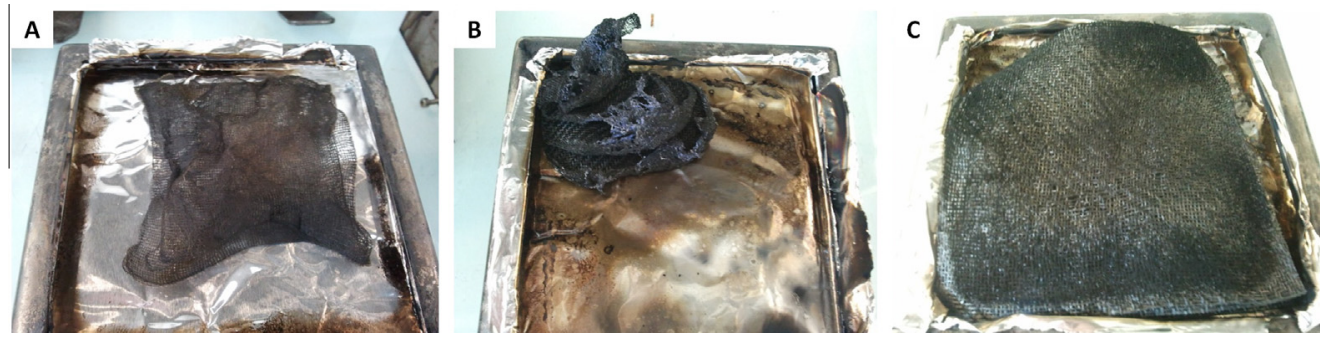

Fig. 16. Residues of (A) PES/F, (B) PES/F-MAPC1 and (C) PES/F-MVP composites after cone calorimeter test.

\section{Conclusions}

Phosphorus flame retardants have been successfully grafted to flax fabrics through e-beam irradiation in air and at low doses. The amount of grafted phosphorus depends on the radiation dose, the concentration of the flame retardant in THF and its nature. These parameters allow controlling precisely the grafting efficiency and then the desired level of flame retardancy. The flame retardant was grafted only onto the surface (MAPC1) or into the bulk (MVP) of flax fibers. In the former case, the phosphorus content was quite low $(<0.4 \mathrm{wt} \%)$. In the latter, the phosphorus content can reach $4 \mathrm{wt} \%$.

MACP1 does not modify significantly the anaerobic degradation of fibers. However, this flame retardant improves the thermo-oxidative stability of the char formed as evidenced in PCFC test. Therefore, the flame retardancy of flax fabric is improved because char is not degraded. Nevertheless self-extinguishment is not reached. When flax fabric is used as reinforcement in a polyester composite, no improvement is observed in cone calorimeter test.

On the contrary, MVP has a greater impact on flame retardancy of flax fabric due to the higher phosphorus content grafted onto fibers. Charring is promoted in anaerobic pyrolysis and thermo-oxidative stability of the char is enhanced. Peak of heat release rate in PCFC is significantly decreased. However, degradation occurs at lower temperature. Flax fabric is self-extinguishing with only $1.5 \mathrm{wt} \%$ of phosphorus. Moreover, in cone calorimeter test, polyester composite containing flax fabric modified with $4.1 \mathrm{wt} \%$ of phosphorus from MVP exhibits a strongly improved behavior: pHRR and THR are decreased by more than $40 \%$. Two phenomena are identified: the charring of fabric and the flame inhibition of fuels by a fraction of phosphorus released in the gas phase. These results are very promising despite a shorter time-to-ignition.

\section{Acknowledgement}

The authors acknowledge the French Fonds Unique Interministériel and the Pôles de Compétitivité for supporting the BIONICOMP project. 


\section{Appendix A. Supplementary material}

Supplementary data associated with this article can be found, in the online version, at http://dx.doi.org/10.1016/j.eurpolymj.2015.05.005.

\section{References}

[1] O. Faruk, A.K. Bledzki, H.-P. Fink, M. Sain, Biocomposites reinforced with natural fibers: 2000-2010, Prog. Polym. Sci. 37 (2012) 1552-1596.

[2] J. Biagiotti, D. Puglia, J.M. Kenny, A review on natural fibre-based composites-Part I, J. Nat. Fibers 1 (2004) 37-68.

[3] D. Puglia, J. Biagiotti, J.M. Kenny, A review on natural fibre-based composites-Part II, J. Nat. Fibers 1 (2005) $23-65$.

[4] D.N. Saheb, J.P. Jog, Natural fiber polymer composites: a review, Adv. Polym. Technol. 18 (1999) $351-363$.

[5] S. Chapple, R. Anandjiwala, Flammability of natural fiber-reinforced composites and strategies for fire retardancy: a review, J. Thermoplast. Compos. Mater. 23 (2010) 871-893.

[6] J. George, M.S. Sreekala, S. Thomas, A review on interface modification and characterization of natural fiber reinforced plastic composites, Polym. Eng. Sci. 41 (2001) 1471-1485.

[7] A. Bledzki, S. Reihmane, J. Gassan, Properties and modification methods for vegetable fibers for natural fiber composites, J. Appl. Polym. Sci. 59 (1996) $1329-1336$.

[8] L. Wojnarovits, C.M. Foldvary, E. Takacs, Radiation-induced grafting of cellulose for adsorption of hazardous water pollutants: a review, Radiat. Phys. Chem. 79 (2010) 848-862.

[9] K. Bocz, B. Szolnoki, A. Marosi, T. Tabi, M. Wladyka-Przybylak, Flax fibre reinforced PLA/TPS biocomposites flame retarded with multifunctional additive system, Polym. Degrad. Stab. 106 (2014) 63-73.

[10] S. Matkó, A. Toldy, S. Keszei, P. Anna, G. Bertalan, G. Marosi, Flame retardancy of biodegradable polymers and biocomposites, Polym. Degrad. Stab. 88 (2005) 138-145.

[11] M. Ragoubi, D. Bienaimé, S. Molina, B. George, A. Merlin, Impact of corona treated hemp fibres onto mechanical properties of polypropylene composites made thereof, Ind. Crops Prod. 31 (2010) 344-349.

[12] J. Gassan, Effects of corona discharge and UV treatment on the properties of jute-fibre epoxy composites, Compos. Sci. Technol. 60 (2000) $2857-2863$.

[13] K. Sever, S. Erden, H. Gülec, Y. Seki, M. Sarikanat, Oxygen plasma treatments of jute fibers in improving the mechanical properties of jute/HDPE composites, Mater. Chem. Phys. 129 (2011) 275-280.

[14] A. Baltazar-y-Jimenez, M. Bistritz, E. Schulz, A. Bismarck, Atmospheric air pressure plasma treatment of lignocellulosic fibres: impact on mechanical properties and adhesion to cellulose acetate butyrate, Compos. Sci. Technol. 68 (2008) 215-227.

[15] F. Khan, Photoinduced graft-copolymer synthesis and characterization of methacrylic acid onto natural biodegradable lignocellulose fiber, Biomacromolecules 5 (2004) 1078-1088.

[16] F. Khan, Characterization of methyl methacrylate grafting onto preirradiated biodegradable lignocellulose fiber by $\gamma$-radiation, Macromol. Biosci. 5 (2005) 78-89.

[17] J.A. Harris, J.C. Arthur, R. Wilton, Flame resistant cotton fabrics prepared by radiation-initiated polymerization with vinyl phosphonate oligomer and Nmethylolacrylamide, J. Appl. Polym. Sci. 23 (1979) 2555-2565.

[18] S.O. Han, D. Cho, W.H. Park, L.T. Drzal, Henequen/poly(butylene succinate) biocomposites: electron beam irradiation effects on henequen fiber and the interfacial properties of biocomposites, Compos. Interfaces 13 (2006) 231-247.

[19] Z.N. Azwa, B.F. Yousif, A.C. Manalo, W. Karunasena, A review on the degradability of polymeric composites based on natural fibres, Mater. Des. 47 (2013) 424-442.

[20] R. Kozlowski, M. Wladyka-Przybylak, Flammability and fire resistance of composites reinforced by natural fibers, Polym. Adv. Technol. 19 (2008) 446453.

[21] N. Suardana, M. Ku, J. Lim, Effects of diammonium phosphate on the flammability and mechanical properties of bio-composites, Mater. Des. 32 (2011) 1990-1999.

[22] G. Dorez, B. Otazaghine, A. Taguet, L. Ferry, J.-M. Lopez-Cuesta, Improvement of the fire behavior of poly(1,4-butanediol succinate)/flax biocomposites by fiber surface modification with phosphorus compounds: molecular versus macromolecular strategy, Polym. Int. 63 (2014) 1665-1673.

[23] G. Dorez, A. Taguet, L. Ferry, J.-M. Lopez-Cuesta, Phosphorous compounds as flame retardants for polybutylene succinate/flax biocomposite: additive versus reactive route, Polym. Degrad. Stab. 102 (2014) 152-159.

[24] G. Dorez, B. Otazaghine, A. Taguet, L. Ferry, J.-M. Lopez-Cuesta, Use of Py-GC/MS and PCFC to characterize the surface modification of flax fibres, J. Anal. Appl. Pyrol. 105 (2014) 122-130.

[25] L. Shimao, R. Jie, Y. Hua, Y. Tao, Y. Weizhong, Influence of ammonium polyphosphate on the flame retardancy and mechanical properties of ramie fiberreinforced poly(lactic acid) biocomposites, Polym. Int. 59 (2010) 242-248.

[26] R. Liepins, J.R. Surles, N. Morosof, V.T. Stannett, Localized radiation grafting of flame retardants to poly(ethylene terephtalate). I. Bromine-containing monomers, J. Appl. Polym. Sci. 21 (1977) 2529-2550.

[27] R. Liepins, J.R. Surles, N. Morosof, V.T. Stannett, Localized radiation grafting of flame retardants to polyethylene terephtalate. II. Vinyl phosphonates, J. Appl. Polym. Sci. 22 (1978) 2403-2414.

[28] A. Mey-Marom, L.A. Rajbenbach, Flame retardance in polyester fabric radiolytically grafted with bromostyrene, J. Appl. Polym. Sci. 28 (1983) 24112424.

[29] K. Kaji, I. Yoshizawa, C. Kohara, K. Komai, M. Hatada, Preparation of flame-retardant polyethylene foam of open-cell type by radiation grafting of vinyl phosphonate oligomer, J. Appl. Polym. Sci. 51 (1994) 841-853.

[30] D. Maldas, B.V. Kokta, J.C. Daneaulf, Influence of coupling agents and treatments on the mechanical properties of cellulose fiber-polystyrene composites, J. Appl. Polym. Sci. 37 (1989) 751-775.

[31] A. Khalil, H.D. Rozman, N.N. Ahmad, H. Ismail, Acetylated plant-fiber-reinforced polyester composites: a study of mechanical, hygro-thermal, and aging characteristics, Polym.-Plast. Technol. Eng. 39 (2000) 757-781.

[32] B.D. Pallensen, The quality of combine-harvested fibre flax for industrials purposes depends on the degree of retting, Ind. Crops Prod. 5 (1996) 65-78.

[33] G. Dorez, L. Ferry, R. Sonnier, A. Taguet, J.-M. Lopez-Cuesta, Effect of cellulose, hemicellulose and lignin contents on pyrolysis and combustion of natural fibers, J. Anal. Appl. Pyrol. 107 (2014) 323-331.

[34] R.E. Lyon, R.N. Walters, Pyrolysis combustion flow calorimetry, J. Anal. Appl. Pyrol. 71 (2004) 27-46.

[35] C. Huggett, Estimation of rate of heat release by means of oxygen consumption measurements, Fire Mater. 4 (1980) 61-65.

[36] C.Q. Yang, Q. He, R.E. Lyon, Y. Hu, Investigation of the flammability of different textile fabrics using micro-scale combustion calorimetry, Polym. Degrad. Stab. 95 (2010) 108-115.

[37] F. Khan, S.R. Ahmad, E. Kronfli, $\Gamma$-Radiation induced changes in the physical and chemical properties of lignocellulose, Biomacromolecules 7 (2006) 2303-2309. 